\title{
Lung Ultrasonography and Chest Radiography in Suspected Cases of Pneumonia in Critically III Patients- A Comparative Study
}

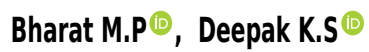 \\ Associate Professor, Department of Radiodiagnosis, Subbaiah Institute of Medical Sciences, Shimoga, Karnataka, India.
}

\section{Abstract}

Background: The present study compared lung ultrasound (USG) and chest radiography in suspected cases of pneumonia in critically ill patients. Subjects \& Methods: 56 patients age above 20 years of age of both genders diagnosed with pneumonia were included. Patients were subjected to chest USG and X ray. Positive predictive values for both lung ultrasound and chest X-ray were calculated. Results: Age group 20-30 years had 4 patients, 30-40 years had 6, 40-50years had 10, 50-60 years had 16 and $>60$ years had 20 patients. The difference was significant $(\mathrm{P}<$ 0.05 ). Chest $x$ ray reveled 40 out of 56 cases positive and 16 negative and USH showed 52 positive and 4 negative. Positive predictive value (PPV) of chest $\mathrm{x}$ - ray was $71.4 \%$ and USG was $92.8 \%$. The difference was significant $(\mathrm{P}<0.05)$. Conclusion: Lung ultrasound is an effective radiological tool for the assessment of suspected cases of pneumonia as compared to chest $\mathrm{x}$ ray.

Keywords: Pneumonia, Lung ultrasound, X-ray

Corresponding Author: Deepak K.S, Associate Professor, Department of Radiodiagnosis, Subbaiah Institute of Medical Sciences, Shimoga, Karnataka, India.

E-mail: dr.deepak.ks@gmail.com

Received: 15 April 2020

Revised: 25 May 2020

\section{Introduction}

Pneumonia is one of the leading causes of death worldwide, and in low-income countries, it is the leading cause of death. These deaths may be prevented by early detection and targeted antibiotic therapy. ${ }^{[1]}$ However, the diagnosis of pneumonia is not always clear on presentation to health care facilities. Diagnosing pneumonia is challenging to physicians, as there is wide variety of conditions to consider in its differential diagnosis, eg, cardiogenic and non-cardiogenic pulmonary edema, malignancy, hemorrhage, pulmonary embolism, and inflammation secondary to noninfectious causes. ${ }^{[2]}$

Patients with acute respiratory symptoms, lung ultrasound (LUS) is a useful test for diagnosing pneumonia, especially when chest $\mathrm{X}$-ray (CXR) results are negative or inconclusive. Guidelines still consider CXR as the reference first-line diagnostic test in all patients with suspected pneumonia. ${ }^{[3]}$ However, its diagnostic accuracy is not optimal, due to high interobserver variability in interpretation.Patient-related factors may also bias the acquisition of a good radiograph, especially in those with severe symptoms. These limitations may increase the number of chest CT prescriptions. ${ }^{[4]}$ Conversely, the routine application of LUS in emergency departments and intensive care units (ICUs) is associated with an improve- ment of diagnostic accuracy for pneumonia and may even in some cases replace CXR, reducing the need of CT scans. ${ }^{[5]}$ The present study compared lung ultrasound (USG) and chest radiography in suspected cases of pneumonia in critically ill patients.

\section{Subjects and Methods}

The present study was conducted in Department of Radio diagnosis, Subbaih Institute of Medical Sciences, Shimoga among 56 patients age above 20 years of age of both genders diagnosed with pneumonia. Patients had at least three of the following signs or symptoms: temperature greater than $38^{\circ} \mathrm{C}$ or history of fever, cough, dyspnea, tachypnea (respiratory rate greater than 20), or oxygen saturation lower than $92 \%$. The enrolled patients were informed regarding the study and their written consent was obtained. Ethical clearance was obtained before starting the study.

Data such as name, age, gender etc. was recorded. Patients were subjected to chest USG. A Sonosite M Turbo ultrasound machine with a curvilinear probe was used. An ultrasound diagnosis of pneumonia was defined as the presence of unilateral B lines or subpleural lung consolidation. All 
patients underwent postero-anterior (PA) chest X-ray. Positive predictive values for both lung ultrasound and chest X-ray were calculated. Results were subjected to statistical analysis. $P$ value less than 0.05 was considered significant.

\section{Results}

\begin{tabular}{|lll|}
\hline \multicolumn{2}{|l|}{ Table 1: Distribution of patients } \\
\hline Total- 56 & \\
\hline Gender & Males & Females \\
\hline Number & 30 & 26 \\
\hline
\end{tabular}

[Table 1] shows that out of 56 patients, males were 30 and females were 26.

\begin{tabular}{|c|c|c|}
\hline $\begin{array}{ll}\text { Age } & \text { group } \\
\text { (Years) } & \end{array}$ & Number & $P$ value \\
\hline $20-30$ & 4 & 0.01 \\
\hline $30-40$ & 6 & \\
\hline $40-50$ & 10 & \\
\hline $50-60$ & 16 & \\
\hline$>60$ & 20 & \\
\hline
\end{tabular}

[Table 2, Figure 1] shows that age group 20-30 years had 4 patients, 30-40 years had 6, 40-50years had $10,50-60$ years had 16 and $>60$ years had 20 patients. The difference was significant $(\mathrm{P}<0.05)$.

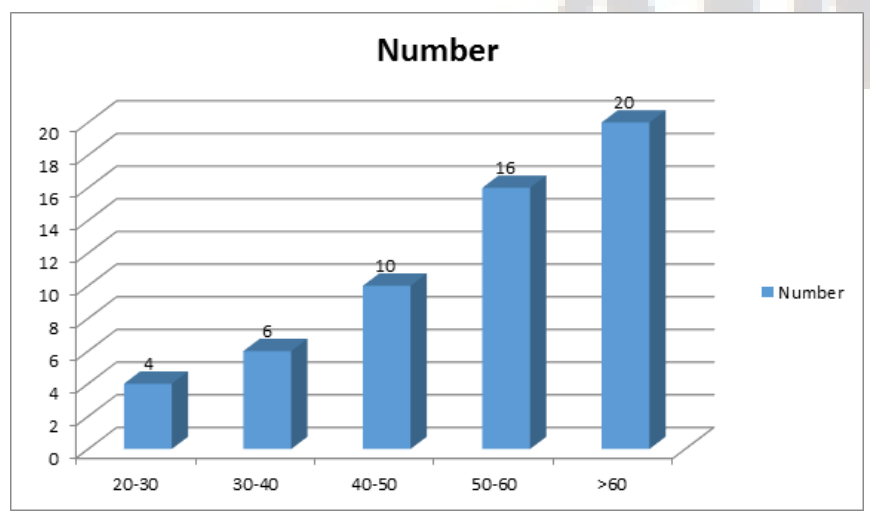

\section{Figure 1: Age wise distribution of cases}

[Table 3] shows that chest $\mathrm{x}$ ray reveled 40 out of 56 cases positive and 16 negative and USH showed 52 positive and 4 negative. Positive predictive value (PPV) of chest $\mathrm{x}$ - ray was $71.4 \%$ and USG was $92.8 \%$. The difference was significant $(\mathrm{P}<0.05)$.

\section{Discussion}

Pneumonia is still a major health care problem, with an important effect on mortality and morbidity worldwide. Pneumonia affects 5.16 to 7.06 people per 1000 person-years, and the rate of pneumonia increases with increasing age. ${ }^{6]}$ Pneumonia is the second-most common type of nosocomial infection of high mortality and is considered an important health care-related complication. ${ }^{[7]}$ Lung ultrasound demonstrated a higher sensitivity for the diagnosis of pneumonia compared to chest Xray. Previous studies have found similar results regarding the sensitivity of ultrasound for pneumonia. ${ }^{[8,9]}$ The present study compared lung ultrasound (USG) and chest radiography in suspected cases of pneumonia in critically ill patients.

In present study, out of 56 patients, males were 30 and females were 26. Age group 20-30 years had 4 patients, $30-40$ years had 6, 40-50years had 10, 50-60 years had 16 and $>60$ years had 20 patients. Bitar et al, ${ }^{[10]}$ found that out of 92 patients with suspected pneumonia, $73(79.3 \%)$ were confirmed to have a diagnosis of pneumonia based on radiological reports, clinical progress, inflammatory markers, and microbiology studies. Of the 73 patients, $31(42.5 \%)$ were male, with a mean age of 68.3 years, and a range of 27 to 94 years. Eleven (15\%) patients had community-acquired pneumonia, and $62(85 \%)$ had hospital-acquired pneumonia. In the group of patients with confirmed pneumonia, 72 (98.6\%) had LUSs positive for consolidation (sensitivity $98.6 \%, 95 \%$ CI $92.60 \%$ $99.97 \%)$, and in the group without pneumonia, $16(85 \%)$ had LUS negative for consolidation compared with $40(55 \%)$ with CXRs positive for consolidation and $33(45 \%)$ with CXRs negative for consolidation. A chest CT was performed in 38 of the 92 enrolled patients and was diagnostic for pneumonia in 32 cases. LUSs were positive in 31 of 32 patients with CT-confirmed pneumonia (sensitivity 96\%), and CXR was positive in 5 of 32 patients with CT-confirmed pneumonia (sensitivity $15.6 \%$ ).

We found that chest $x$ ray revealed 40 out of 56 cases positive and 16 negative and USH showed 52 positive and 4 negative. Positive predictive value (PPV) of chest $\mathrm{x}$ - ray was $71.4 \%$ and USG was $92.8 \%$. Ticinesi et al, ${ }^{[11]}$ enrolled $169(80 \mathrm{M}, 89 \mathrm{~F})$ multimorbid patients aged $83.0 \pm 9.2$ years. Each participant underwent CXR and bedside LUS within 6 hours from ward admission. LUS was performed by skilled clinicians, blinded to CXR results and clinical history. The final diagnosis (pneumonia vs no-pneumonia) was established by another clinician reviewing clinical and laboratory data independent of LUS results and possibly prescribing chest contrast-enhanced CT. Diagnostic parameters of CXR and LUS were compared with McNemar test on the whole cohort and after stratification for Rockwood Clinical Frailty Scale. Diagnostic accuracy for pneumonia (96 patients) was significantly higher in LUS (0.90, 95\% confidence interval [CI] 0.83-0.96) compared with CXR. LUS had a better sensitivity and negative predictive value. In 


\begin{tabular}{lllc|}
\hline Table 3: Comparison of USG and Chest X ray with CT & & \\
\hline \multirow{2}{*}{ Chest X- ray } & Radiographs & CT positive (56) & PPV \\
& Positive & 40 & $71.4 \%$ \\
\multirow{2}{*}{ Ultrasound } & Negative & 16 & $92.8 \%$ \\
& Positive & 52 & \\
\hline
\end{tabular}

those patients with frailty ( $\mathrm{n}=87$ with Rockwood Clinical Frailty Scale $\geq 5$ ), LUS maintained a high diagnostic accuracy, but $\mathrm{CXR}$ did not $(\mathrm{P}=0.0003)$. Interobserver agreement for LUS, calculated in a subsample of 29 patients, was high $(\mathrm{k}=$ 0.90).

Amatya et $\mathrm{al}^{[12]}$ found that of 62 patients included in the study, 44 (71\%) were diagnosed with pneumonia by CT. Lung ultrasound demonstrated a sensitivity of $91 \%$ compared to chest X-ray which had a sensitivity of $73 \%(\mathrm{p}=0.01)$. Specificity of lung ultrasound and chest X-ray were 61 and $50 \%$ respectively.

The shortcoming of the study is small sample size.

\section{Conclusion}

Authors found that lung ultrasound is an effective radiological tool for the assessment of suspected cases of pneumonia as compared to chest $\mathrm{x}$ ray.

\section{References}

1. Grossman RF, Hsueh PR, Gillespie SH, Blasi F. Communityacquired pneumonia and tuberculosis: differential diagnosis and the use of fluoroquinolones. Int J Infect Dis. 2014;18:14 21. Available from: https://dx.doi.org/10.1016/j.ijid.2013.09. 013.

2. Nyamande K, Lalloo UG, John M. TB presenting as community-acquired pneumonia in a setting of high TB incidence and high HIV prevalence. Int J Tuberc Lung Dis. 2007;11(12):1308-1321.

3. Lichtenstein DA, Lascols N, Mezière G, Gepner A. Ultrasound diagnosis of alveolar consolidation in the critically ill. Intensive Care Med. 2004;30(2):276-281. Available from: https://dx.doi. org/10.1007/s00134-003-2075-6.

4. Long L, Zhao HT, Zhang ZY, Wang GY, Zhao HL. Lung ultrasound for the diagnosis of pneumonia in adults: A metaanalysis. Medicine (Baltimore). 2017;96(3):5713. Available from: https://doi.org/10.1097/md.0000000000005713.

5. Kim HY, Song KS, Goo JM, Lee JS, Lee KS, Lim TH. Thoracic sequelae and complications of tuberculosis. Radiographics. 2001;21(4):839-58. Available from: https://doi.org/10.1148/ radiographics.21.4.g01j106839.

6. Volpicelli G, Elbarbary M, Blaivas M, Lichtenstein DA, Mathis G, Kirkpatrick AW. International evidence-based recommendations for point-of-care lung ultrasound. Intensive
Care Med. 2012;38(4):577-91. Available from: https://doi.org/ 10.1007/s00134-012-2513-4.

7. Vollenweider DJ, Jarrett H, Steurer-Stey CA, Garcia-Aymerich J, Puhan MA. Antibiotics for exacerbations of chronic obstructive pulmonary disease. Cochrane Database Syst Rev. 2012;12:10257. Available from: https://dx.doi.org/10.1002/ 14651858.cd010257.

8. Jones BP, Tay ET, Elikashvili I, Sanders JE, Paul AZ, Nelson BP, et al. Feasibility and Safety of Substituting Lung Ultrasonography for Chest Radiography When Diagnosing Pneumonia in Children. Chest. 2016;150(1):131-138. Available from: https://dx.doi.org/10.1016/j.chest.2016.02.643.

9. Hagaman JT, Panos RJ, Rouan GW, Shipley RT. Admission Chest Radiograph Lacks Sensitivity in the Diagnosis of Community-Acquired Pneumonia. Am J Med Sci. 2009;337(4):236-240. Available from: https://dx.doi.org/10. 1097/maj.0b013e31818ad805.

10. Bitar ZI, Maadarani OS, El-Shably AM, Al-Ajmi MJ. Diagnostic accuracy of chest ultrasound in patients with pneumonia in the intensive care unit: A single-hospital study. Health Sci Rep. 2019;2(1):102. Available from: https://dx.doi.org/10. 1002/hsr2.102.

11. Ticinesi A, Lauretani F, Nouvenne A, Mori G, Chiussi G, Maggio M, et al. Lung ultrasound and chest x-ray for detecting pneumonia in an acute geriatric ward. Medicine. 2016;95(27):4153. Available from: https://dx.doi.org/10.1097/ md.0000000000004153.

12. Amatya Y, Rupp J, Russell FM, Saunders J, Bales B, House DR. Diagnostic use of lung ultrasound compared to chest radiograph for suspected pneumonia in a resource-limited setting. J Emerg Med. 2018;11:8-8. Available from: https://dx.doi.org/10.1186/ s12245-018-0170-2.

Copyright: (C) the author(s), 2020. It is an open-access article distributed under the terms of the Creative Commons Attribution License (CC BY 4.0), which permits authors to retain ownership of the copyright for their content, and allow anyone to download, reuse, reprint, modify, distribute and/or copy the content as long as the original authors and source are cited.

How to cite this article: Bharat M.P , Deepak K.S . Lung Ultrasonography and Chest Radiography in Suspected Cases of Pneumonia in Critically Ill Patients- A Comparative Study. Asian J. Med. Radiol. Res. 2020;8(2):88-90.

DOI: dx.doi.org/10.47009/ajmrr.2020.8.2.14

Source of Support: Nil, Conflict of Interest: None declared. 